of the air above surrounding districts of the coal measures, or statistics of the fertility and periods of fructification of crops under similar differences of conditions. Of course the great difficulty affecting the last point is the difference in the chemicai constitution of the soils produced by the decomposition of trap and stratified rocks.

Edinburgh, June 2 I

\section{Winters and Summers}

A FRIEND writes to me :- "From my observations of climate here (Belfast) I should say that I never saw a severe winter followed by a really fine summer. The severest winters I remember were those of I $554-5$, and $1859-60$. The summer of 1855 was very wet, and that of I $\$ 60$ deplorable. The finest summers I remember were those of $1 S_{42}, 1857$, and 1865 ; in every case the preceding winter was very mild."

I would add to thi, that the severe winters of $186 ;$ and IS 70 were not followed by remarkably fine summers. The harvest weather of 1866 was unusually bad.

Can any of your readers throw light on this subject from carefully kept registers?

Old Forge, Dunmurry, June 6

\section{Cyclones}

Mr. MAURY's theory of Cyclones, as stated in NATURE of the $19^{\text {th }}$, is, in my opinion, true and valuable. I hope you will pernit me to call the attention of your readers to my letter in Nature, Vol. iv. p. 305 , where it will appear that $I$ had independently arrived at the conclusion stated by him, "that the origin of cyclones is found in the tendency of the south-east trade-winds to invade the north-east trades by sweeping over the equator into our hemispheres." Only the words "south-east" and "north-east" must exchange places, and "the opposite hemisphere," must be read, instead of " our hemisphere," if we are to apply the theory to the cyclones of the Southern Indian Ocean and of the Southern Pacific. On this latter subjest, see Mr. Whitmee's letter in WNATURE, vol. vi. p. I2r.

I wish, however, to call your attention to what I think an error in the diagram of the winds, which Mr. Maury reprints from Prof. Ferrel. It represents the winds at the surface of the earth in the Polar regions as blowing in nearly the same direction as the trade winds. This appears mechanically impossible, and I cannot think that Prof. Coifin's data are extensive enough as regards the Polar regions. As the late Capt. Maury remarks, the west winds of the higher and middle latitudes constitute "an everlasting cyclone on a great scale ;" that is to say, a vast vortex whereof the pole is the centre. But it appears impossible that the direction of the motion of a vortex should be reversed at its centre.

Old Forge, Dunmurry, June 24

\section{A Mirage in the Fens}

$\Lambda$ s the phenomenon called Mirage is not very common in this co:mtry, though more frequent in the Fens, perhaps, than elsewhere, I presume that a description of one which was seen on Thursday, May 29, last, will be interesting to the readers of NATURE.

Driving from Wisbech towards Thorney on the morning named, I stopped at Guyhirne, and my friend, Mr. S. B. J. Skertchley, of H. M. Geulogical Survey, who accompanied me, mounted the parapet of the bridge of the March and Spaldin Railway, to view the Fens from that elevation, and then called my attention to what appeared a beautiful lake spread out a few miles distant. The illusory waters were of a bluish grey colour, and being apparently raised from the level, presented the perspective of a Mlere of considerable breadth. But this was not a dull expanse; there were variously formed indentations-islands dotted here and there, pollard willows inverted, and the reflection of tall poplars and elms on the glassy surface. The use of my field-glass only brought these features more distiactly to the eye. As we stood on the bridge, we were looking from W. by S. to W. Whittlesea Church was eight miles distant, and Thorney Abbey seren miles. The mirage was stretched out from Eastern Fen ower l'rior's Fen to the west of Thorney, i.e. three or four miles. It was II o'clock. There was a fresh breeze from N.E. ; the sky was not half obscured by cloud; the barometer stood high, being four degrees difference between the dry and wet bulb thermometers at 9 A.x. All these conditions were favourable to evaporation; there had been more than half an incly of rain the Monday previous. Mr. S. had witnessed a similar phenomenon from another point of view (see Nature, vol. ii. p. 337) in $1 S_{j 0}$, when he saw it both $\mathrm{E}$. and W. of his position, but on Thursday last there was not even a mist in any other part of the horizon. On both occasions the wind was N.E. It may be interesting to know whether these phenomena appear with a mild and moist S.TV, or W. breeze.

Wisbech, June 5

SAMIL. H. MIILLER

\section{The Westerly Progress of Cities}

ReFerRixg to Mr. W. F. Barrett's letter I would remark that there is a similar phrase, viz. the westerly or north.westerly progress of nations, which is intimately connected with "the westerly progress of cities," and the former helps to explain the latter. As a rule the more westerly of two peoples inhabiting a country is there by compulsion, laving been driven thither by the invader who, as a rule, makis the attack from the east. The remnants of the ancient Celtic race, inhabiting portions of the western shores and highlands of Spain, France, and the British Isles, are an evidence of this. We sce the same process going on now in Amcrica : the aborigines being driven befure the invader, to the west. There are insignificant exceptions, both in ancient and modern times, but they only prove the rule.

So much then for the westerly among the peop!es of a land: they are in the west by violent compuision. Anong the inhabitants of a city the westerly are there also by compulsion-not a compulsion by violence, but by uncomfortable pressure; in which case it is the powerful or wealthy who retire before the weaker or poorer.

The very fact of the westerly progress of nations establishes the further fact that what becomes afterwards more or less the eastern part of the city is the older and that whare the first habitations were erected. An exception would be such a case as a city built on a western coast without any adjacent country to the west. Ilere the wealthy in retiring before their less fortunate fellow-citizens must necessarily go more or less. to the east.

London, June 9

To the instances of "westing" adduced by MIr. W. F. Barrett as occurring in the large towns of the Old Norld it is desirable to add that a similar tendency prevails in the large towns of the New, excepting, of course, the cases in which physical barritrs impede or prevent it.

It should be observed, also, that this westward current of progress in cities appears to be but the special manifestation of a principle much more general-the direction of great enigrations and of the advance of civilisation, apjarently in pre-historic and certainly throughout historical times, having been uniformly towards the west.

G. J. R.

\section{How does the Cuckoo deposit her Eggs?}

A FEv days ago while examining a reed bed in the fons of Lincolnshire, near Wainfleet, I found a Reed V'arbler's nest, in which was deposited a Cuckoo's egg. From the shafe of the nest, which was very narrow and deep, and from the position of the nest, which was built on slender reeds, on the outer edge of the bed, it was utterly impossible that the egg could have been laid, as, in the first place, the nest was far tou small for so large a bird as the cuckoo to sit in; and in the second, the weight of the bird would have inevitably swamped the nest. Does not this fact go far, at any rate, to confirm the theory held by many ornithologists to be the correct one, that the female cuckoo drops her esrgs into nests by means of her bill, as it is well known she is provided by Nature with an enlargement in the throat, in which the egg could be carried in safety during her flight in search of a suitable place in which to deposit it. I give here a quotation from Bewick on the subject :-

"Naturalists are not agreed as to whether the female cuckoo lays her egg at once in the ncst of another bird, or whether she lays it first on the ground, and then, seizing it with her bill, conveys it in her throat (supposed to be enlarged for this purpose) to the nest which is to be its depository."

1 should be glad if any of your correspondents will inform me if the male bird las a like enlargement in the throat, or is it only to be found in the hen?

Regent's Terrace, Hull 